\title{
O ABUSO DE DROGAS E O MUNDO DO TRABALHO: POSSIBILIDADES DE ATUAÇÃO PARA O ENFERMEIRO
}

\author{
Drug Abuse and Workplace: \\ Possibilities to Nurse Actuation \\ El Abuso de Drogas y el Mundo del Trabajo: \\ Posibilidades para la Actuación del Enfermero
}

Lucia Maria Beck'

Helena Maria Scherlowski Leal David²

\section{Resumo}

Este artigo é uma análise reflexiva sobre o uso e abuso de substâncias psicoativas, definido como farmacodependência, e o mundo do trabalho contemporâneo. Tem como objetivo contribuir para que o enfermeiro do trabalho construa uma estratégia prática que possibilite a avaliação dos níveis de dificuldades do usuário de drogas para o exercício pleno de atividades laborais, permitindo a elaboração de intervenções adaptativas para a reinserção deste usuário no mundo do trabalho atual, globalizado, dinâmico e ágil, baseado no paradigma da redução de danos para a promoção da saúde e resgate da cidadania.

Palavras-chave: Transtornos Relacionados ao Uso de Substâncias. Local de Trabalho. Redução do Dano. Enfermagem do Trabalho.

Abstract

This article is a reflexive analysis about psychoactive drugs addiction, defined as substance-related disorders, and the contemporaneous workplace. Its objective is to contribute that the nurse of occupational health nursing build a practical strategy to make possible the evaluation of the drug addicts' problems level related to workplace, in order to adapt interventions to put back addicts in current workplace, which is globalized, dynamic and agile, based in harm reduction paradigm to the promotion of health and citizenship rescue.

\section{Resumen}

Este artículo es una análisis reflexiva sobre el uso y abuso de sustancia psicoactivas, definido como dependencia farmacológica, y el mundo del trabajo contemporáneo. Tiene como objetivo contribuir para que el enfermero del trabajo construya una estrategia práctica que posibilite la evaluación de los niveles de dificultades del usuario de drogas para el ejercicio lleno de las actividades del trabajo, permitiendo la elaboración de intervenciones de adaptación para la reinserción del usuario en el lugar de trabajo actual, globalizado, dinámico y ágil, basado en el paradigma de la reducción de daños para la promoción de la salud y rescate de la ciudadanía.
Keywords: Substance-Related Disorders. Workplace. Harm Reduction. Occupational Health Nursing.
Palabras clave: Trastornos Relacionados con Sustancias. Lugar de Trabajo. Reducción del Daño. Enfermería del Trabajo. 


\section{INTRODUÇÃO}

Este artigo traz uma análise reflexiva sobre a relação entre o uso e abuso de substâncias e o mundo do trabalho contemporâneo, na perspectiva da atuação do enfermeiro, nas diversas áreas de intervenção: administrativa, assistencial, educativa, de pesquisa, de assessoria e de auditoria.

Entendemos que esta relação não está construída a priori, e que é preciso contextualizar o debate, tendo em vista os novos paradigmas orientadores de políticas e ações de saúde, e os desafios que o tema impõe à Enfermagem brasileira. Refletir sobre as situações relacionadas ao uso e abuso de drogas em sua complexidade permitirá ao enfermeiro, no âmbito do trabalho em equipe interdisciplinar, construir estratégias mais efetivas de promoção da saúde, prevenção de riscos e intervenção sobre danos.

Em 1969, a Organização Mundial de Saúde (OMS) definiu o conceito de farmacodependência, enfatizando a interação do medicamento ou substância com o organismo, associada à compulsão, uso freqüente, alterações psíquicas, instalação de tolerância e síndrome de abstinência. A OMS considera o uso de drogas um problema de saúde pública, estimando que $10 \%$ da população dos grandes centros urbanos consome drogas abusivamente ${ }^{1}$, fato este que produz implicações sociais, psicológicas, econômicas e políticas.

A farmacodependência, ou abuso de drogas, produz uma dinâmica de intenso sofrimento orgânico e psíquico do indivíduo e também traz inseridas alterações multidimensionais, refletidas em toda a sociedade, na família, nos estudos, no trabalho. Essas influências se tornaram tão profundas e importantes que atualmente inúmeras organizaç̃̃es governamentais e não governamentais de todo o mundo se preocupam com o assunto.

0 mundo do trabalho sofreu, nas duas últimas décadas, transformaações profundas, que resultaram em mudanças nas formas de contratação e emprego, e nos modos de desempenhar e vender a mão-de-obra ${ }^{2}$. Conseqüentemente, as características necessárias ao trabalhador, para adaptar-se a um novo mercado de trabalho, também passaram a ser bem peculiares. Oliveira ${ }^{3}$ argumenta que a flexibilização do contrato de trabalho acabou com a distinção formal entre tempo trabalhado e tempo ocioso, entre emprego e desemprego, aumentando a produtividade e criando o chamado "trabalho abstrato" e modificando as relações sociais. Essa realidade exige uma grande capacidade de adaptação do indivíduo, no sentido de rever sua concepção de vida, para inserir-se adequadamente no mundo do trabalho. É fácil observar que um indivíduo com as relações sócio-afetivas comprometidas, como é o caso do usuário de drogas, tem maior dificuldade de adaptação.

Especificamente quanto à situação de farmacodependência, o profissional de enfermagem pode se inserir profundamente na lacuna que se criou entre o usuário de drogas e o mundo do trabalho, servindo como ponte sólida, alicerçada na integração de saberes que estimulem a autonomia e organização do indivíduo para ingressar, manter-se ou retornar ao mundo do trabalho.

\section{ABUSO DE DROGAS: CONTEXTOS E CARACTERÍSTICAS}

0 consumo de drogas sempre esteve presente na história da humanidade, porém era vinculado a rituais religiosos, o que favorecia o seu controle 4 . Atualmente, devido à oferta e variedade de drogas acessíveis em todas as camadas sociais, no contexto consumista da sociedade contemporânea, o uso desvinculou-se de outras atividades sociais, passando a justificar-se por si próprio.

A dependência química é o resultado do encontro de uma droga, uma personalidade e um meio sócio-cultural ${ }^{4}$, sendo a droga uma porção química, um objeto, um produto inerte que sempre esteve presente na história da humanidade e na própria natureza. A personalidade é própria e exclusiva do ser humano, o que o diferencia e o destaca de todos. 0 meio sócio-cultural é - espaço onde este ser transita, interage, se relaciona, influencia e é influenciado, expondo suas potencialidades e vulnerabilidades que são dinâmicas e variáveis. Portanto, não existe um fator preponderante que determine a dependência química, mas uma confluência de fatores e condições internas e externas que produzirá o usuário de drogas dependente químico.

Um homem em cada cinco utiliza a droga para ter acesso a algo diferente do que está habituado a ver e a pensar ${ }^{5}$, porém, o uso constante e abusivo desta droga provoca alterações psicoativas e desloca as relações que este homem tem, denegrindo e depauperando a sua qualidade de vida em todas as dimensões orgânica, familiar e social.

Destacam-se quatro fatores principais que reforçam a exclusão social do usuário de drogas, de acordo com o Ministério da Saúdé:

1. Associação do uso de álcool e outras drogas à delinquiência...;

2. Os estigmas atribuídos aos usuários, promovendo a sua segregação social;

3. Inclusão do tráfico como alternativa de trabalho e geração de renda para as populações mais empobrecidas...;

4. A licitude do uso impede a participação social de forma organizada.

Estas características produzem um quadro de desorganização, com diferentes níveis de comprometimento, percebidos sintomaticamente como: aumento do absenteísmo no trabalho, incapacidade de cumprir as tarefas/metas estipuladas, perda do emprego, negligência dos papéis sociais, interrupção dos estudos, adoecimento das relações familiares, descompromisso financeiro, subordinação a subempregos, desvalorização da auto-imagem, traços depressivos e sentimentos de caráter negativo com maior freqüência. Afinal, o tempo despendido para a obtenção e consumo da droga e o próprio tempo sob o seu efeito conduzem a uma reordenação dos hábitos de vida diária, em que a prioridade desloca-se para a própria droga e 0 circuito social marginalizado que a envolve.

$\mathrm{Na}$ América Latina, a situação de alguns países como produtores centrais de droga ilícita e como rota do tráfico constitui-se em um problema que é acrescentado à histórica situação de dificuldades econômicas e problemas sociais.

Além do que, até mesmo entre os grupos populacionais, alguns são considerados mais vulneráveis que outros: baixa 
escolaridade, pobreza e desemprego figuram entre as variáveis de risco citadas. Vale ressaltar que o tipo de droga consumida também difere entre os estratos sociais e as regiões do país. Em recente levantamento domiciliar, Carlini ${ }^{7}$ conclui que 0 álcool segue sendo a droga mais consumida e mais freqüentemente considerada "de risco" pelos entrevistados.

A violência é o problema mais importante e grave relacionado ao tráfico, sendo a sua associação ao uso considerada pouco conclusiva ${ }^{8}$. A violência urbana e doméstica é o evento mais visível e mais freqüentemente associado ao uso de drogas, mas há outros tipos de violência que continuam a ser pouco compreendidos, como a violência no ambiente do trabalho.

Verifica-se, assim, que o contexto do abuso de substâncias é multifacetado, não sendo possível ignorar, nas análises que visam à compreensão deste fenômeno, a dimensão do trabalho humano - tanto do ponto de vista das conseqüências do uso e abuso, que podem afetar as relações e ações do trabalho, como da própria participação dos fatores de organização e desenvolvimento do trabalho como elementos capazes de participar na complexa determinação da farmacodependência.

\section{O MUNDO DO TRABALHO HOJ E: MUDANÇAS E IMPASSES}

Após a Segunda Grande Guerra, o mundo do trabalho caracterizou-se por padronização no contrato de trabalho, na duração da jornada de trabalho e em relação ao lugar do trabalho. Predominavam as negociações de contrato coletivas, e o padrão de "emprego seguro", localizado nas grandes empresas, constituía-se no sonho dos trabalhadores em geral.

A partir dos anos de 1970, as características inerentes ao novo trabalhador mudaram radicalmente, passando 2 "o mundo do trabalho a ser povoado por indivíduos independentes, automotivados, que tomam suas decisões a partir de interesses e preferências individuais".?

0 processo de globalização não pode ser examinado apenas sob seus aspectos financeiros. A reorientação de relações de mercado entre países que teve lugar nas últimas décadas também se acompanhou de mudanças sociais, principalmente nos países em desenvolvimento. Para autores como Belinguer ${ }^{9}$, estas mudanças vieram aprofundar a distância entre os países mais pobres e o mundo rico, em função de uma crescente concentração de poder e capital nas mãos de poucos atores.

A incapacidade de os Estados latino-americanos controlarem os fluxos financeiros, agora sob o controle do capital internacional, levou esses mesmos Estados a também subordinar os assuntos sociais e políticos, fazendo as adaptações necessárias. 0 assim chamado ajuste macroeconômico ou ajuste estrutural que teve lugar desde a década de 1980 trouxe mudanças na política econômica destes países, que, por usa vez, produziram impacto nas políticas de bem-estar social ${ }^{10}$. As conseqüências mais dramáticas são a subcontratação, a precarização e a flexibilização das relações de trabalho, além do aumento nas taxas de desemprego.

Temos, na atualidade, a valorização do serviço autônomo, por projeto, por prazo determinado ou por subcontrato. 0 salário fixo já não é a forma mais importante de remuneração, e sim a remuneração variável, por tarefa ou produtividade.
Dentre as características de maior importância em relação ao novo mundo do trabalho, destaca-se a valorização de atributos pessoais como aparência, idade, educação, gênero e raça, transformados em potencial produtivo, fazendo com que os valores intrínsecos do indivíduo sejam os fatores mais importantes de empregabilidade. As relações de amizade, o ambiente familiar e os contatos sociais em geral formam uma verdadeira rede que facilita, sobremaneira, a obtenção de empregos. Como afirma Sorj², hoje em dia, o próprio trabalhador é parte do produto que está sendo oferecido ao cliente.

0 conceito de "trabalho emocional" criado por Hochschild associa, obrigatoriamente, o comportamento do empregado às emoções do cliente ${ }^{11}$. Por esse motivo, 0 atual trabalhador necessita de equilíbrio emocional e capacidade expandida de julgamento, para ter chances razoáveis no mundo do trabalho.

De modo complementar, há um consenso de que trabalhadores desempregados têm menor auto-estima ou maior sentimento depressivo, apresentam menor nível de bem-estar, experimentam sentimentos de caráter negativo mais freqüentemente, sentem menor grau de satisfação com a vida, além de apresentarem uma imagem mais negativa de si mesmos e de menos valia quando comparados com trabalhadores empregados, fato este que levaria a uma dificuldade maior de retornar ao mercado de trabalho. Portanto, o trabalho pode ser considerado importante fator de proteção e manutenção da saúde mental.

Ricardo Antunes e Giovanni Alves ${ }^{12}$ indicam que apesar de a classe trabalhadora atual "não ser idêntica à existente em meados do século passado, ela também não está em vias de desaparição", há uma propensão a se confirmarem as tendências atuais, tais como: redução do proletariado industrial estável a partir do desenvolvimento do lean production, formas de horizontalização do capital produtivo, flexibilização e desconcentração do espaço produtivo e introdução do maquinário informatizado. Paradoxalmente, ocorreu o aumento do proletariado fabril e de serviços caracterizados pelo incremento da oferta de trabalho precarizado. E ganhou significância a força de trabalho feminino, prioritariamente no universo do trabalho temporário e desregulamentado, tendo como conseqüência níveis salariais, direitos sociais e trabalhistas desiguais, quando comparados aos trabalhadores do sexo masculino.

Fator importante também é a exclusão dos jovens com idade para ingressarem no mercado de trabalho, devido ao desemprego estruturante e dos adultos acima dos quarenta anos de idade, considerados "idosos", que, se demitidos, dificilmente conseguem uma nova recolocação, pois há uma tendência a substituir este profissional especializado, herdeiro da cultura fordista, pelo trabalhador polivalente e multifuncional da era toyotista. Este fato reforça alternativas criativas e adaptadoras, tais como o emprego informal, o trabalho voluntário e o trabalho no Terceiro Setor, que é um desdobramento direto da retração do mercado industrial e de serviços ${ }^{12}$. Por outro lado, o trabalho juvenil, entre jovens que têm de associar uma jornada de trabalho a uma de estudo, foi identificado como sendo uma situação potencialmente geradora de maior estresse e pressão social ${ }^{13}$. 
Ocorreu, ainda, a expansão do trabalho doméstico como conseqüência das novas características do mundo do trabalho e do aprimoramento da teleinformática. Houve um terreno propício para que as atividades do trabalho produtivo se realizassem no espaço doméstico ou em pequenas unidades produtivas.

Há, ainda, uma última tendência, no contexto do capitalismo mundializado e na transnacionalização do capital e do sistema produtivo: o mundo do trabalho organiza-se em fronteiras diferentes dos limites geográficos, em que o antigo status "MADE IN" desvalorizou-se em relação ao conceito de "produzido com os melhores incrementos a nível mundial".

As tensões decorrentes deste processo de reorganização produzem, por sua vez, novas subjetividades no mundo do trabalho. Por um lado, exige-se que o trabalhador se inscreva de modo criativo e autônomo no processo de produção; por outro lado, a imposição de pressões produtivas e sociais é por vezes intolerável, e pode levar a rupturas graves da integridade física e psíquica do trabalhador.

\section{O USO ABUSIVO DE DROGAS E O MUNDO DO TRABALHO}

Produz-se, no âmago das relações esfaceladas que permeiam o mundo do trabalho de hoje, uma situação-dilema para o trabalhador: enfrentar o desemprego, ou reorganizarse, interna e externamente, para adequar-se às novas regras do processo produtivo, o que se dá, com freqüência, às custas de sua força vital. No entanto, reconhece-se que, mesmo sob pressão, o trabalhador tece estratégias de enfrentamento, individuais e coletivas. Tal situação, já exaustivamente apontada como capaz de afetar a saúde do trabalhador, pode constituir-se em elemento condicionante para o uso abusivo de drogas, lícitas ou ilícitas.

Em relação ao álcool, reconhece-se o consumo e, eventualmente, o uso abusivo e a dependência, associada, com freqüência, a determinados comportamentos sociais característicos dos trabalhadores, tais como as confraternizações e encontros sociais após o horário do trabalho. Entre jovens estudantes que também trabalhavam, Soldera ${ }^{13}$ encontrou maior associação entre o consumo de álcool do que entre os que não trabalhavam. 0 autor atribui este resultado a uma possível incorporação, entre estes estudantes, de um comportamento social característico do adulto trabalhador, além da capacidade de consumo ampliada pelo fato de receberem um salário mensal. São bem conhecidos os relatos sobre o uso de anfetaminas entre trabalhadores do setor de transporte - os chamados "rebites" - e entre os que desenvolvem suas atividades em turnos sucessivos, tais como os profissionais de saúde.

No ambiente de trabalho, a proximidade com o usuário ou a naturalização de alguns comportamentos não permitem, com freqüência, a identificação das situações de abuso de droga. 0 comportamento diferente ou as atitudes estranhas são explicados por questões externas à utilização da droga e, quando relacionados, já podem constituir-se em dependência profunda e crítica. Esta condição, por sua vez, tende a ser reconhecida com maior clareza, sobretudo em função de seus efeitos na produtividade do trabalhador, expressando-se em absenteísmo, atrasos, aumento na ocorrência de acidentes, ações inadequadas e conflitos interpessoais.

Às dificuldades e pressões cotidianas somam-se as que são impostas a um indivíduo, em relação às suas atividades laborais, pelo simples fato de ser usuário de drogas. É prática corrente do usuário de drogas omitir a sua condição com receio de represálias que poderiam, até mesmo, representar a perda do emprego. É importante salientar que esta prática resulta numa postergação do tratamento. Vale lembrar que, numa fase mais precoce da dependência, na qual a saúde não está tão comprometida, a abordagem terapêutica tende a ser mais produtiva.

As alterações físicas, o comprometimento social e as perturbações psicológicas causadas pelo uso freqüente da droga com o decorrer do tempo interferem a tal ponto no desempenho profissional, que fica evidente, então, a patologia que será agora abordada terapeuticamente, em uma fase na qual o tratamento não poderá mais evitar a perda de produtividade do indivíduo. Em alguns casos, tais como o de servidores públicos, já não há como demiti-lo, não só porque essa prática o prejudicaria mais ainda, mas porque a lei já não o permitiria. 0 tratamento passa, então, a ser mais dispendioso, sendo freqüentemente desenvolvido com 0 indivíduo afastado das atividades profissionais.

Pelo exposto, fica claro que tanto as dificuldades impostas pelo mundo do trabalho ao usuário de drogas quanto a submissão do mesmo a essas dificuldades fazem com que a produtividade seja afetada, trazendo prejuízos evidentes a todos os envolvidos na questão. Entretanto, o reconhecimento sobre a situação deste trabalhador, de modo a mantê-lo conscientemente integrado à sua prática laboral, mostra a possibilidade de se encarar o trabalho como parte integrante das ações terapêuticas, gerando vantagens também para 0 empregador. Note-se que, nesta perspectiva, não se espera que 0 indivíduo abandone primeiramente as drogas para inseri-lo no mercado, e sim, usa-se a atividade laboral entendendo-a como dimensão fundamental da vida humana, capaz de atuar como elemento catalisador de forças e como redução de danos. A propósito, devemos argumentar que políticas governamentais capazes de regular especificamente essa condição trabalhista precisariam ser desenvolvidas.

\section{POSSIBILIDADES PARA A ATUAÇÃO DO ENFERMEIRO}

A partir das modificações que ocorreram nas relações de trabalho, e da própria forma de adaptação a este novo mundo laboral, como discutido anteriormente, os profissionais de saúde ocupacional, incluindo o enfermeiro, perceberam-se em um contexto com transição do perfil epidemiológico dos trabalhadores, refletindo estas mudanças.

Trata-se, pois, de situação que exige um enfermeiro com capacidade de atuação multidisciplinar. Além dos conhecimentos específicos na área de álcool e drogas, vale lembrar que é desejável que este profissional possua, também, conhecimentos 
que possibilitem o aproveitamento de ferramentas práticas, como o trabalho, que possam ser utilizadas em favor de uma estratégia de redução de danos.

A perspectiva de atuação descrita busca contemplar a integração do enfermeiro nas ações específicas da enfermagem do trabalho, desenvolvida nos programas de saúde ocupacional nas empresas e serviços, bem como nos serviços de Atenção Básica do Sistema Único de Saúde (SUS) que hoje compõem a rede de Atenção em Saúde do Trabalhador. Na função administrativa, o enfermeiro poderá desenvolver ações para influenciar na cultura institucional, a fim de possibilitar 0 desenvolvimento de programas de redução de danos para o trabalhador usuário de drogas. $\mathrm{Na}$ assistencial, a avaliação deve ser individualizada, mas sempre relacionada com a patologia em evidência no ambiente de trabalho, tendo uma visão ampliada e entrelaçada com a investigação, o diagnóstico, a implementação de resoluções e a manutenção da saúde, e sempre respeitando a subjetividade do indivíduo.

No âmbito da educação de saúde no trabalho, o fortalecimento da capacidade cognitiva e de estratégias coletivas de enfrentamento de dificuldades e pressões pode resultar na ampliação da capacidade produtiva e da autonomia dos trabalhadores, valorizados como sujeitos autônomos e capazes de desenhar e desenvolver processos de autoregulação da atividade do trabalho. Neste sentido, não apenas as relações interpessoais ou os aspectos da organização do processo de trabalho devem ser levados em conta, mas também as condições ambientais nas quais se desenvolve a atividade de trabalho. Vale lembrar que garantir um "bom ambiente de trabalho" não inclui escamotear os conflitos ou desqualificar as críticas dos trabalhadores, e sim incorporar estes elementos em processos transparentes de negociação e construção de consensos.

Com base nas atividades propostas para o enfermeiro do trabalho para a assistência ao trabalhador alcoolista, organizadas por Donato ${ }^{14}$, que preconiza a avaliação e 0 acompanhamento sistemático e integral deste trabalhador para resguardá-lo de possíveis danos decorrentes deste consumo, deve-se estender estas intervenções ao trabalhador usuário de outras substâncias psicoativas (SPA) como um todo, tendo como patamar sólido o paradigma da redução de danos, visando o resgate (ou a conquista) da saúde em seu conceito amplo. Para isto, o enfermeiro pode atuar como condutor ou estrategista na construção de um mapa de possibilidades, serviços e recursos sociais dentro e fora do ambiente de trabalho, sempre sensível ao sofrimento e a demanda, incluindo também nesta cartografia a família do trabalhador. Pesquisas, como a proposta neste trabalho, contribuem para a construção do sólido conhecimento das necessidades do trabalhador objetivando, então, ações de intervenção.

A prevenção de riscos voltada para o uso abusivo de substância demanda a ampliação do conhecimento acerca dos efeitos farmacológicos e do contexto sócio-cultural envolvidos no uso das diversas drogas disponíveis, e a identificação de riscos potenciais ou reais, relacionados ao trabalho ou a aspectos pessoais do trabalhador. 0 enfoque de risco não pode, no entanto, confundir-se com uma ação de fiscalização ou normatização de comportamentos e hábitos. Vale lembrar que a identificação de riscos, na perspectiva da saúde do trabalhador, deve envolver, necessariamente, o olhar do próprio trabalhador acerca das condições que considera perigosas ou facilitadoras do uso abusivo de substâncias, o grupo familiar, a participação de gestores e líderes e a sociedade como um todo. Para tanto, a assessoria prestada pelo enfermeiro do trabalho aos vários segmentos é fundamental.

É ainda primordial que o enfermeiro do trabalho seja o fiscalizador das ações de enfermagem implementadas, pois é o único profissional com o conjunto necessário de conhecimentos que permitem a coordenação integrada das atividades, para se lograr o êxito necessário.

Por último, embora não menos importante, defende-se a idéia de que as ações voltadas para o enfrentamento do problema do uso abusivo de drogas por trabalhadores devem ser desenvolvidas num contexto participativo, descentralizado e resolutivo. A inserção do enfermeiro na atual política de Saúde do Trabalhador, organizada pela Rede Nacional de Atenção Integral à Saúde do Trabalhador (RENAST) busca romper com os paradigmas da "medicalização" e "biologização" dos processos envolvendo trabalho e saúde, avançando rumo a uma compreensão ampla e solidária das questões envolvidas neste campo. Nesse sentido, o enfermeiro do trabalho, pelas características integradoras do trabalho de enfermagem, tornase elemento relevante no contexto das equipes em Saúde do Trabalhador em todos os níveis, desde a gestão federal ou estadual até os núcleos locais, atualmente em processo de estruturação nos municípios brasileiros.

\section{CONCLUSÃO}

0 uso abusivo, ou não, de drogas é uma realidade crescente profundamente em nossa sociedade. Esta conduta, por si só, possibilita identificar indivíduos com características comportamentais e sociais diferenciadas, inclusive no mundo do trabalho; portanto, requer maior atenção da sociedade para seu tratamento e recuperação. As estratégias atuais e as que devem ser construídas para enfrentar o problema passam pela valorização da ocupação e do trabalho do indivíduo, visando aumentar a sua autoestima, melhorar os seus níveis de positividade em relação ao mundo que o cerca, incrementando os relacionamentos sociais produtivos.

Ao mesmo tempo, sabe-se que o enfrentamento das condições estruturais que geram a desigualdade e a opressão dos trabalhadores não pode deixar de ser reconhecido e fortalecido, já que este enfrentamento expressa, em boa medida, a vocação do trabalhador para a atuação autônoma e responsável, como produtor da realidade, e não apenas reprodutor de condições predeterminadas.

Paradoxalmente, a sociedade altamente consumista que gera a procura pela droga, cria exigências que dificultam e/ou até impedem o acesso dos usuários de droga ao mundo do trabalho atual, quando exige as mesmas características hígidas, de alta performance, para estar no mundo do trabalho, as quais o usuário de drogas carece e, justamente, busca como objetivo final ao almejar inserir-se no mercado produtivo. 
Portanto, é importante adequar as propostas de reinserção social, ligadas à terapêutica do usuário de drogas, às reais exigências do atual mundo laboral, aprofundando o conhecimento sobre este indivíduo, suas expectativas e necessidades, para viabilizar sua adaptação ao atual mercado produtivo e manter sua saúde mental contribuindo com uma possível evolução pessoal positiva.

0 enfermeiro do trabalho reúne a formação adequada para intermediar a relação entre o usuário de drogas e seu empregador, pois, com conhecimentos na área da saúde e do

\section{Referências}

1 Organização Mundial de Saúde- OMS. Comite de Expertos de la OMS en Farmacodependencia: $18^{\circ}$ Informe. Genebra; 1971: 1-48. Série de Informes Técnicos.

2 Sorj B. Sociologia e trabalho: mutações, encontros e desencontros. Rev Bras Cienc Soc 2000 jun; 15 (43): 25-34

3 Oliveira F. 0 ornitorrinco: crítica à razão dualista. São Paulo (SP): Boitempo; 2003

4 Acselrad G, organizador. Avessos do prazer: drogas, AIDS e direitos humanos. Rio de Janeiro (RJ): FIOCRUZ; 2000.

5 Baptista M, Cruz MS, Matias R, organizadores. Droga e pósmodernidade. Rio de Janeiro (RJ). EdUERJ; 2003.

6 Ministério da Saúde (BR) Secretaria de Atenção à Saúde. A política do Ministério da Saúde para atenção integral a usuários de álcool e outras drogas. Brasília (DF); 2004. trabalho, pode atuar nas áreas: administrativa, assistencial, educativa, de pesquisa, assessoria e auditoria, aproveitando, assim, seu conhecimento científico, redimensionando-o para interferir de maneira prática e positiva nas relações do trabalhador usuário de drogas com o mundo do trabalho, tornando-a mais saudável de forma a contribuir efetivamente na recuperação do indivíduo. Assim, no mundo produtivo, um grupo que antes não era aproveitado poderá ser incluído responsavelmente, obtendo lucros tanto para si quanto para o empregador, com repercussão positiva para a sociedade em geral.

7 Carlini EA. $2^{\circ}$ Levantamento Domiciliar sobre o Uso de Drogas Psicotrópicas no Brasil, 2005. Brasília (DF): SENAD; 2007.

8 Minayo MCS, Deslandes SF. The complexity of relations between drugs, alcohol, and violence. Cad Saude Publica 1998 janmar; 14 (1): 35-42.

9 Berlinguer G. Globalization and global health. Int J Health Serv 1999; 29 (3): 579-95.

10 Costa NR. Política social e ajuste macroeconômico. Cad Saude Publica 2002;18 (supl): 13-21.

11 Hochschild AR. The managed heart: commercialization of human feelings. Berkeley (CA): University of California Press; 1983.

12 Antunes R, Alves G. Globalização e educação: precarização do trabalho docente. Educ.Soc. 2004; maio/ago; 25 (87): 2-4

13 Soldera M. et al. Use of psychotropic drugs among students: prevalence and associated social factors. Rev Saude Publica 2004 abr; 38 (2): 277-84

14 Donato M. Reinserção do trabalhador alcoolista no contexto laboral: a percepção do enfermeiro do trabalho. [tese de doutorado]. Rio de Janeiro (RJ): Escola de Enfermagem Anna Nery/ UFRJ; 2002. 